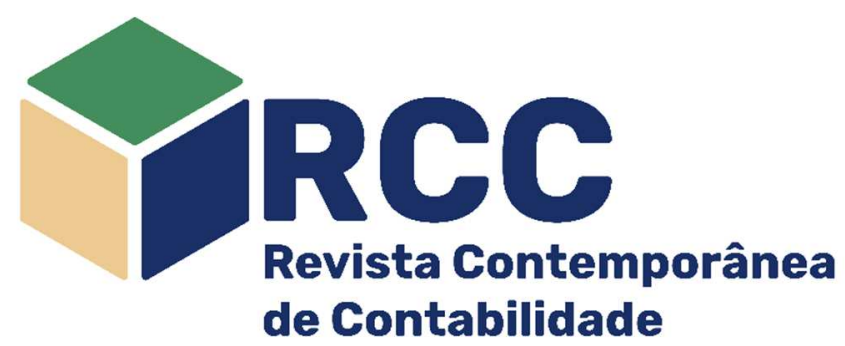

\title{
Fatores contingenciais que contribuem para a adoção do custeio alvo: estudo de caso em uma empresa de serviços
}

\author{
Contingency factors that contribute to the adoption of target costing: a case study in a service \\ company
}

Factores de contingencia que contribuyen a la adopción del costeo objetivo: un estudio de caso en una empresa de servicios

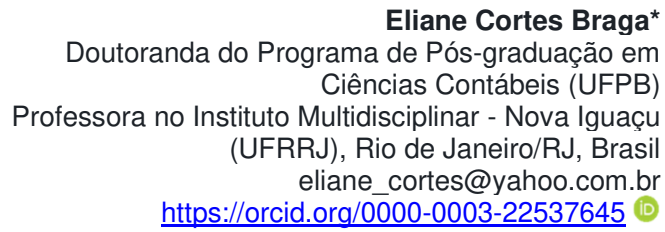

\section{Resumo}

O objetivo desse trabalho foi analisar a influência dos fatores contingenciais no sistema de custeio alvo de uma empresa prestadora de serviços no Estado do Rio de Janeiro. A pesquisa realizada foi um estudo de caso em uma empresa de consultoria em Tecnologia da Informação onde foram coletadas informações por meio de entrevistas acerca de aspectos contingencias (ambiente, tecnologia, estrutura e estratégia) e de atributos relacionados ao sistema de custeio alvo. Para a análise das informações coletadas foi considerada a técnica de análise de conteúdo. Os resultados demonstram que a empresa estudada está inserida em um setor dinâmico, a tecnologia em suas atividades é muito presente. Trata-se de uma empresa de médio porte com razoável descentralização e que atribui muita importância a gestão estratégica de custos. O sistema de custeio alvo é considerado pelos entrevistados como de grande relevância para gerenciar custos e alcançar os objetivos da organização.

Palavras-chave: Custeio Alvo; Fatores contingenciais; Empresas de serviços

\section{Abstract}

The objective of this work was to analyze the influence of contingency factors in the target costing system of a service provider company in the State of Rio de Janeiro. The research carried out was a case study in an information technology consulting company where information was collected through interviews about contingency aspects (environment, technology, structure and strategy) and attributes related to the target costing system. For the analysis of the collected information, the content analysis technique was considered. The results demonstrate that the studied company is inserted in a dynamic sector, the technology in its activities is very present. It is a medium-sized company with reasonable decentralization and which attaches great importance to strategic cost management. The target costing system is considered by the interviewees as of great relevance to manage costs and achieve the organization's objectives.

Keywords: Target Costing; Contingency factors; Service companies

\section{Resumen}

El objetivo de este trabajo fue analizar la influencia de los factores de contingencia en el sistema de costeo objetivo de una empresa proveedora de servicios en el estado de Río de Janeiro. La investigación realizada fue un estudio de caso en una empresa de consultoría de tecnología de la información donde se recopiló 
información a través de entrevistas sobre aspectos de contingencia (medio ambiente, tecnología, estructura y estrategia) y con el sistema de costeo objetivo. Para el análisis de la información recopilada, se consideró la técnica de análisis de contenido. Los resultados demuestran que la empresa estudiada se inserta en un sector dinámico, la tecnología en sus actividades está muy presente. Es una empresa con una descentralización razonable y que otorga importancia a la gestión estratégica de costos. Los entrevistados consideran que el sistema de costeo objetivo es de gran relevancia para gestionar los costos y alcanzar los objetivos.

Palabras clave: Costeo objetivo; Factores de contingencia; Empresas de servicios

\section{Introdução}

Nas últimas décadas a Contabilidade Gerencial buscou desenvolver novas ferramentas para gerar informações relevantes em um ambiente em constante mudança e marcado pela competição. O ABC, o Custeio Alvo e o Balanced Scorecard são exemplos dessas novas metodologias. E, desde então muitas pesquisas tem sido desenvolvidas com o intuito de verificar a utilização dessas práticas nas organizações.

No âmbito organizacional, a geração de informações sobre custos assume um papel relevante para que se possa tomar decisões adequadas que posteriormente impactarão a realização dos objetivos propostos da empresa e, também, o desempenho obtido. Como um instrumento no controle de custos, a contabilidade gerencial representa um meio estratégico que contribui para tomar as melhores decisões e indicar as ferramentas necessárias para melhorar o desempenho e a lucratividade da organização.

Neste contexto, o Custeio Alvo tem se configurado como um importante método para gestão de custos. Sob o sistema de custeio alvo, as atividades são controladas usando uma meta, ou um custo admissível baseado no mercado, que deve ser realizado para que a empresa seja lucrativa. Uma margem de lucro desejada é subtraída do preço de venda estimado para determinar o custo alvo para o novo produto. Todos os membros da organização trabalham subsequentemente para projetar e fabricar o produto com o custo desejado (Gagne \& Discenza, 1995).

De maneira semelhante às demais, empresas prestadoras de serviços também precisam dispor de informações para melhorar a qualidade, pontualidade e eficiência das atividades que executam, além de compreender de modo mais preciso o custo e a lucratividade de cada um de seus clientes. Segundo Berts e Kock (1995), o aumento da concorrência também impactou o setor de serviços fazendo com que os gerentes atribuíssem maior importância ao uso das informações contábeis, principalmente as informações sobre custos, para planejamento, controle e tomada de decisão.

Durante a última parte do século XX, o setor de serviços cresceu significativamente em praticamente todos os países desenvolvidos, com os Estados Unidos, por exemplo, representando quase $80 \%$ da fonte de emprego no ano de 2000 (Heineke \& Davis, 2007). Segundo Heineke e Davis (2007), esse crescimento foi causado por vários fatores, incluindo mudança no estilo de vida da população, desregulamentação e infraestrutura nova e melhorada, incluindo a ampla disponibilidade de novas tecnologias. No Brasil, o setor de serviços também apresenta grande relevância em relação ao PIB, com uma representatividade de $72,5 \%$ no $1^{\circ}$ Trimestre de 2018 , seguido pelo setor da indústria que apresentou participação de $20,8 \%$, enquanto o setor de agropecuária representou apenas 6,7\% (Sebrae, 2018).

De acordo com Negri \& Kubota (2006), o aumento da participação do emprego e do valor agregado dos diversos serviços prestados vem dando visibilidade ao setor, contribuindo para uma melhor compreensão das características específicas de suas atividades, bem como para aplicação de conceitos básicos de gestão em seu ambiente de negócios, reconhecendo a necessidade de uma abordagem adequada às características particulares dessas operações.

As razões que influenciam a adoção de determinadas práticas em uma organização podem não ser as mesmas que em outra e, além disso, a relação entre os fatores envolvidos faz com que existam diferenças entre as organizações (Marques, 2012). De um modo geral, o mercado é regido pelo enfoque da eficiência; por isso, as organizações procuram meios de reduzir as incertezas a fim de aplicar os recursos e obter vantagem competitiva. Sendo assim, identificar, analisar e interpretar os fatores contingentes que podem influenciar na adoção e utilização de métodos, como o custeio alvo, torna-se importante para verificar a adequação ao um sistema de controle apropriado aos fatores contingenciais existentes na organização para esta possa ser ainda mais eficiente (Donaldson, 2007; Marques, 2012).

A partir da Teoria da Contingência, percebe-se que não existe uma estrutura única que seja apropriada para todas as organizações e que a otimização de uma estrutura depende de fatores internos à organização, que por sua vez sofrem influência do ambiente (Donaldson, 2007). Segundo Donaldson (2007), diversos fatores são denominados contingentes, tais como: estratégia, porte, incerteza com relação às tarefas, tecnologia, dentre outros. Para uma organização ser eficaz, se espera que ela adeque sua estrutura a seus fatores internos e ao ambiente de negócios no qual ela esteja inserida.

Para Marques (2012) a compreensão de como essas práticas conquistam a atenção dos atores organizacionais e como elas são implementadas e desenvolvidas continua a ser uma fonte interessante de 
pesquisa, ademais, uma das finalidades da pesquisa em contabilidade gerencial deveria ser a determinação de quais práticas funcionam e em que circunstâncias e como mudar as práticas nas organizações.

De acordo com Ax, Greve e Nilsson (2008), a partir da década de 1990, os pesquisadores tentaram identificar os fatores que podem influenciar as decisões de uma empresa em adotar técnicas modernas de controle de custos e gerenciamento. Alguns estudos buscaram investigar a influência dos fatores contingenciais na adoção do custeio alvo, dentre eles, os de Ax et al. (2008), Marques (2012), Rasit e Ismail (2017), Marques e Rocha (2017) e Brizolla et al. (2017), os resultados apresentaram vários fatores influentes.

Infelizmente, embora muitas empresas usem o custeio alvo, há pouca evidência sobre os fatores que influenciam a decisão de uma empresa de adotá-lo ou rejeitá-lo (Ax et al., 2008). Além disso, nenhuma das pesquisas citadas teve como foco uma empresa do setor de serviços. Todavia, há algumas pesquisas que buscaram verificar a utilização do custeio alvo por empresas de serviços, tais como a de Camacho e Rocha (2008) no ramo de serviços hospitalares e a de Lemos Júnior e Colauto (2013) em uma instituição de ensino superior. Os resultados de tais estudos apontaram o custeio alvo como uma ferramenta útil para a organização.

Devido a existência de diversas dimensões dos sistemas de informações gerenciais e as frequentes mudanças no ambiente das organizações, novos estudos sob o enfoque da Teoria da Contingência são necessários, além disso, há uma necessidade de mais pesquisas sobre organizações de serviços e sem fins lucrativos, uma vez que essas entidades se tornam cada vez mais importantes na maioria das economias (Chenhall, 2003). Diante desse contexto, o objetivo dessa pesquisa é analisar a influência dos fatores contingenciais na adoção do custeio alvo em uma empresa prestadora de serviços.

O estudo foi realizado em uma empresa prestadora de serviços de consultoria que atua no segmento de Tecnologia da Informação (TI). Esse segmento passou a ser um importante componente competitivo para as organizações diante da contínua evolução da tecnológica, permitindo melhorar e modernizar cada vez mais os meios de informação e comunicação dos mais diversos setores. A partir dos achados desta pesquisa, as empresas de serviços poderão observar a influência de fatores contingenciais na adoção de uma ferramenta de controle gerencial como o custeio alvo, bem como observar como tais aspectos podem contribuir e estimular a adoção desse método.

\section{Referencial Teórico}

\subsection{Teoria da Contingência}

A Teoria da Contingência foi mencionada pela primeira vez em estudos de administração na década de 1960, que criticavam as teorias universais e apresentava essa teoria como um instrumento útil para melhorar as teorias de administração (Porporato \& Waweru, 2011). A premissa básica fundamental é que as variáveis da organização têm uma inter-relação complexa entre elas e com as condições do ambiente (Porporato \& Waweru, 2011). Essa teoria supõe que as condições do ambiente provocam mudanças no interior das organizações e para maximizar o seu desempenho é preciso que as empresas se adaptem a seu ambiente (Silva et al., 2014).

Com a Teoria da Contingência surge o conceito de fatores contingenciais que são a chave para a definição do sistema mais adequado que irá contribuir para o desempenho da empresa (Donaldson, 2007). E assim sendo, com base nessa teoria, busca-se entender de que maneira as empresas se ajustam a esses fatores contingentes, tais como: porte, setor de atuação, intensidade da concorrência, incerteza ambiental, tecnologia, postura estratégica, dentre outros (Camacho, 2010; Silva et al., 2014).

A proposição central da teoria da contingência afirma que o desempenho organizacional depende do ajuste entre o contexto organizacional e a estrutura (Cadez \& Guilding, 2008). As variáveis contingenciais típicas, como tecnologia, ambiente e estratégia, podem ser vistas como medidas do nível de complexidade que as organizações enfrentam (Donaldson, 2007). No entanto, a estrutura sugere que o que guiará os requisitos de processamento de informações das organizações é a incerteza e que ela é causada não apenas pela interação de vários fatores contextuais externos, mas também por fatores como o nível de conhecimento organizacional e a compreensão de como isso afeta os processos internos (Chapman, 1997).

Dessa forma, estudos sobre fatores contingenciais auxiliam na definição do melhor caminho a seguir para atingir os objetivos e metas das organizações. Observar, categorizar e analisar os fatores contingenciais em que a organização está inserida poderá contribuir para um maior desempenho socioeconômico da empresa (Camacho, 2010).

De acordo como Donaldson (2007), no âmbito dos estudos organizacionais, a Teoria da Contingência tem fornecido um paradigma coerente para a análise das estruturas das organizações. Essa teoria estabelece que não exista uma estrutura organizacional única que seja altamente efetiva para todas as organizações, mas uma organização ótima é aquela contingente aos fatores contingenciais. A abordagem de contingência expressa que, uma vez que as organizações são diferentes, comparadas em termos de tamanho, objetivos de negócios a serem alcançados, atividades e tarefas a serem executadas e outras situações que surgem, é estranho aplicar princípios aplicáveis universalmente que funcionem para contingências ou situações que surgem nas várias organizações (Sandoval, 2013). 
De uma forma geral, as pesquisas que utilizam o paradigma da contingência na área dos estudos organizacionais desde o início de sua evolução relacionam os fatores contingentes à estrutura organizacional com a finalidade de explicar a forma da organização. De modo semelhante, fatores contingentes foram relacionados a aspectos da Contabilidade Gerencial (Chapman, 1997; Chenhall, 2003; Marques, 2012). Assim, a abordagem de contingência se tornou o paradigma dominante na pesquisa empírica em contabilidade (Cadez \& Guilding, 2008).

Chenhall (2003) faz uma revisão com o intuito de contribuir na compreensão dos fatores contingenciais, denominado por ele como "variáveis contextuais", são elas: ambiente, a tecnologia, a estrutura, o tamanho e a estratégia. O ambiente externo, segundo Chenhall (2003), é uma variável contextual influente que está na base da pesquisa baseada em contingência e que possivelmente o aspecto mais amplamente pesquisado do ambiente seja a incerteza. O autor ainda faz distinção entre a incerteza e o risco, em que risco pode ser relacionado a situações nas quais as probabilidades podem ser anexadas a eventos específicos, enquanto que a incerteza define situações nas quais as probabilidades não podem ser anexadas e até mesmo os elementos do ambiente podem não ser previsíveis. Sendo assim, o ambiente é tido como um fator contingente externo à organização e conforme o ambiente sofre mudanças, influencia o interior das empresas, dessa forma, as empresas precisam compreender esse ambiente para diminuir a incerteza (Beuren \& Fioretin, 2014).

A tecnologia se refere à maneira pela qual os processos de trabalho da organização operam, ou seja, como as tarefas transformam entradas em saídas, bem como inclui hardware (como máquinas e ferramentas), materiais, pessoas, software e conhecimento (Chenhall, 2003). A tecnologia foi um dos primeiros fatores contingenciais a serem estudados e tem sido caracterizada de várias maneiras, medidas típicas diferenciam entre séries pequenas e grandes, processos individuais ou produção em massa (Porporato \& Waweru, 2011).

Com relação à estrutura organizacional, este fator diz respeito a especificação formal de diferentes funções para membros da organização, ou tarefas para grupos, para garantir que as atividades da organização sejam realizadas (Chenhall, 2003). Ainda conforme o mesmo autor, os arranjos estruturais influenciam a eficiência do trabalho, a motivação dos indivíduos, fluxos de informação e sistemas de controle e podem ajudar a moldar o futuro da organização. A estrutura organizacional também está entre os primeiros fatores estudados a partir da Teoria da Contingência e consiste em variáveis da organização ou unidade, como o tamanho da empresa, complexidade da unidade de negócio, variedade de produtos ou serviços, grau de autonomia, diversificação e estrutura (multi-divisão ou por funções) (Porporato \& Waweru, 2011).

Outro fator contingencial diz respeito ao tamanho da organização. O crescimento em tamanho permitiu que as empresas aperfeiçoassem sua eficiência, oferecendo oportunidades de especialização e divisão do trabalho (Chenhall, 2003). À medida que a organização se torna maior, a necessidade de lidar com maiores quantidades de informações aumenta a ponto de instituir controles como regras, documentação, especialização de papéis e funções, hierarquias ampliadas e descentralização ainda maior de estruturas hierárquicas (Chenhall, 2003; Beuren \& Fioretin, 2014). O aumento de tamanho de uma empresa tornará a sua estrutura organizacional mais complexa; consequentemente pode haver aumento no número de funcionários, maior formalização dos processos e ampliação no nível de controle de gestão (Silva et al., 2014).

Por outro lado, estratégia apresenta-se um pouco diferente dos demais fatores contingenciais, pois, em certo sentido, não é considerada como um elemento de contexto propriamente dito, mas sim o meio pelo qual os gerentes podem influenciar a natureza do ambiente externo, as tecnologias da organização, os arranjos estruturais e a cultura de controle e o sistema de controle gerencial (Chenhall, 2003). O papel da estratégia é importante, pois aborda a crítica de que a pesquisa baseada em contingência pressupõe que 0 sistema de controle gerencial de uma organização é determinado pelo contexto e que os gerentes são capturados por sua situação operacional (Chenhall, 2003).

A teoria da contingência é capaz de explicar as causas que levam uma organização a reagir ao ambiente e a decidir na implementação de um determinado sistema de contabilidade gerencial, ou abandonar sistemas tradicionais (Guerreiro; Pereira \& Rezende, 2005). Marques (2012) afirma que a utilização da Teoria da Contingência pode ajudar a entender as situações em que se podem promover a adoção e o uso de uma prática de controle gerencial como o custeio alvo.

Para Marques (2012), nos ambientes marcados pela incerteza ambiental, o custeio alvo é tido como uma prática apropriada devido ao tipo de informação que apresenta. Esse artefato está ligado profundamente à estratégia empresarial e é considerado uma ferramenta estratégica de gestão de custos para atingir o lucro alvo especificado no planejamento organizacional. O custeio alvo é o elo entre a formulação da estratégia e sua execução e geração de lucro e tanto influencia quanto sofre influência da estratégia organizacional (Marques, 2012).

\subsection{Custeio Alvo}

O custeio alvo foi inventado pela Toyota em 1965, estendendo-se pelas indústrias japonesas, especialmente a indústria automotiva, na década de 1970 e, de acordo com Everaert et al. (2005), esse método tornou-se popular na literatura de língua inglesa na década de 1990 através das pesquisas de Cooper (1995), Kato (1993) e Monden e Hamada (1991). 
O custeio alvo tem sido reconhecido como uma ferramenta importante para reduzir custos e aumentar a competitividade por mais de uma década (Ellram, 2002). Trata-se de uma técnica de gerenciamento de custos usada durante o desenvolvimento de novos produtos (NPD): uma meta de custo é definida para um novo produto e a equipe da NPD é motivada a atingir essa meta antes do lançamento do produto (Everaert et al., 2005).

De acordo com Manzanares, Molina e Fernández (2001) o custeio alvo tem sido interpretado a partir de diferentes pontos de vista, segundo a cultura empresarial, pois, as diferentes definições desse conceito vão desde uma simples técnica de cálculo de custos, até serem identificadas como parte do sistema de gerenciamento de benefícios estratégicos. No entanto, deve ser enfatizado que o custeio alvo oferece maiores possibilidades como uma ferramenta de gerenciamento do que como uma técnica de cálculo de custos (Manzanares et al., 2001).

O processo de custeio alvo tem por objetivo reduzir os custos de ciclo de vida dos produtos nas fases anteriores à produção assegurando qualidade, confiabilidade e outros requisitos dos clientes, mas não se limita somente a isso, ele faz parte de um abrangente gerenciamento estratégico do lucro (Kato, 1993). Para Feil, Yook e Kim (2004) sua finalidade é entendida como a de minimizar os custos do ciclo de vida para que o lucro a longo prazo seja maximizado. Para atingir esse objetivo, o cálculo de custos teórico leva em conta não apenas os custos de produção, mas também os custos incorridos em todo o ciclo de vida do produto (Feil et al., 2004).

Para Rocha e Martins (1998), a implantação e execução de um processo de custeio alvo baseia-se em três premissas, são elas: I) O lucro é a garantia de sobrevivência da empresa; II) O custo é definido antes do início da produção; e III) O custo é fortemente influenciado pela competição. Os autores ressaltam que para que o uso do custeio alvo seja eficaz alguns princípios devem ser seguidos: deve enfocar o consumidor; deve atingir toda a cadeira de valor; deve considerar o custo total de propriedade; e requer o envolvimento da empresa como um todo (Rocha; Martins, 1998).

Gopalakrishnan; Samuels e Swenson (2007) consideram que o processo de custeio alvo pode ser dividido em cinco etapas, a saber: 1) definir o novo produto; 2) estabelecer um preço de venda alvo; 3) calcular o custo desejado; 4) decompor o custo alvo por componente; e 5) custos de projeto. Os autores destacam ainda seis princípios-chave que devem ser observados no processo de custeio alvo: custeio baseado em preços; concentre-se nos clientes; foco no design; equipes multifuncionais; orientação do ciclo de vida; e envolvimento da cadeia de valor.

Conforme Gagne e Discenza (1995), o custeio alvo é um método de gestão voltado para o mercado. Dessa forma, o processo de custeio alvo começa estabelecendo um preço de venda, baseado em pesquisa de mercado, para o novo produto. Isto é, inicia-se com o desenvolvimento de uma compreensão das necessidades não atendidas no mercado e a determinação do que os clientes pagariam para que suas necessidades sejam atendidas, o "preço-alvo" (Ellram, 2002).

Há duas etapas principais no cálculo de custos alvo: a primeira é determinar o preço alvo e a margem de lucro de um produto para que o custo alvo possa ser determinado; e, a segunda é decompor o custo alvo até o componente e o nível de matéria-prima para que os preços de compra desses itens possam ser determinados (Gagne \& Discenza, 1995; Ellram, 2002).

No mesmo sentido, Cooper (1996) afirma que o custo alvo de um produto é determinado pela subtração da margem de lucro desejada do preço de venda desejado: custo alvo = preço alvo - margem alvo; o preço-alvo de um novo produto é determinado principalmente pela análise de mercado; e, a margem alvo é definida com base nas expectativas de lucros corporativos, resultados históricos, análise competitiva e, às vezes, simulações de computador. Uma vez que o preço teórico do novo produto foi determinado, ele é usado como base para determinar o preço de compra de componentes e matérias-primas adquiridas externamente (Cooper, 1996).

Na tentativa de alcançar o custo desejado, conforme Gagne e Discenza (1995), a organização realiza análises de custo funcional. Sendo assim, se a estimativa de custo atual estiver sido alcançada, a empresa deve decidir se deve ou não introduzir o novo produto; se, no entanto, o cálculo de custos atual estiver acima da meta, a análise de custos funcionais será usada para fazer alterações e preparar outro cálculo de custos (Gagne \& Discenza, 1995). Uma vez atingidos os custos alvos, o item entra em produção e medidas de melhoria contínua são implementadas (Ellram, 2002).

A análise de custos funcionais é uma atividade de grupo que normalmente envolve funcionários de diferentes departamentos (como marketing, design, engenharia, produção, compras e contabilidade) e tem como objetivo propor alternativas para reduzir o custo total do produto (Gagne \& Discenza, 1995). A análise funcional está intimamente ligada à engenharia de valor (EV) e trata-se de um sistema de gerenciamento de custos que se concentra nas várias funções de cada produto (Gagne \& Discenza, 1995). A EV, às vezes chamada de análise de valor, é uma técnica para avaliar o projeto de um produto para garantir que as funções essenciais sejam fornecidas com custo geral mínimo para o fabricante e o usuário (Chen \& Chung, 2002).

As tabelas de custo são instrumentos para medir de modo fácil e preciso os custos para materiais, peças e atividades auxiliares; tais tabelas são indispensáveis em empresas que utilizam o custeio alvo (Sakurai, 1997). A tabela de custos é um exemplo famoso de informações de custo, usado principalmente por empresas japonesas durante o cálculo de custos alvo (Everaert et al., 2005). 
Tanto a contabilidade de custos quanto a gestão de suprimentos desempenham um papel fundamental na divisão dos custos-alvo entre várias atividades, componentes e materiais (Ellram, 2002). A contabilidade gerencial pode desempenhar um papel importante na determinação efetiva dos lucros alvo e dos custos alvo. Contadores podem fornecer as informações necessárias para apoiar uma análise de marketing de um novo produto e relacioná-lo a produtos existentes (Gagne \& Discenza, 1995).

Ellram (2002) destaca que o custeio alvo é uma ferramenta e uma filosofia valiosas para apoiar os esforços gerais da organização para manter os custos competitivos e, ao mesmo tempo, atender às demandas do cliente. Contudo, de acordo com a autora, o custeio alvo não é um esforço autônomo, mas sim um processo que é mais efetivamente realizado por equipes multifuncionais, em conjunto com outros processos que agregam valor, como envolvimento antecipado do fornecedor, análise de valor e engenharia de valor. Dessa forma, o custeio alvo deve ser estudado e executado a partir de uma perspectiva de equipe holística; ou seja, muitas funções desempenham um papel crucial e dão uma contribuição importante para o processo de custeio pretendido (Ellram, 2002).

\subsection{O Setor de Serviços}

O setor de serviços é o principal destino dos investimentos diretos estrangeiros no Brasil, o qual recebe mais de $60 \%$ destes investimentos e também é o setor a que pertencem os cinco segmentos de negócios de maior ocorrência de fusões e aquisições no país, a saber: por ordem, tecnologia da informação, serviços auxiliares, serviços financeiros, varejo e serviços públicos (eletricidade, gás, rodovias, etc.) somados, eles correspondem por mais de $50 \%$ das operações no Brasil (Santos, 2016).

O setor apresenta ainda grande relevância em relação à criação de empresas, geração de empregos e para o PIB brasileiro. De acordo com o SEBRAE (2018), no 1ำ Trimestre de 2018 o setor de serviços obteve $72,5 \%$ de representatividade no PIB, enquanto que a indústria apresentou participação de $20,8 \%$ e a agropecuária representou apenas $6,7 \%$.

Na visão de Negri \& Kubota (2006) o aumento da participação do emprego e do valor agregado dos serviços vem contribuindo para uma melhor compreensão das características específicas das atividades do setor e com isso, recebe ainda mais relevância. Além disso, pode-se considerar que uma das razões principais para o forte desempenho do setor de serviços nos últimos anos é a influência da globalização, principalmente, das mudanças tecnológicas, como a digitalização dos serviços, a emergência de redes de banda larga e a utilização de Big Date (Negri \& Kubota, 2006).

Com a automação dos serviços a tecnologia está presente nas organizações em diversas áreas, funções e atividades. Dessa forma, em busca de maior eficiência, qualidade na entrega dos serviços e redução dos custos, muitas empresas denominam uma área específica ou empresas responsáveis pelos sistemas, denominada como a área de Tecnologia da Informação (Lacity \&Willcocks, 2017).

No que diz respeito aos serviços relacionados à Tecnologia da Informação, Santos (2016) constata que tem havido um crescimento constante do setor nos últimos anos. Por exemplo, a quantidade de empresas teve um acréscimo de $34 \%$ entre anos de 2007 e 2013 e que esse crescimento tem sido de modo sustentando, uma vez que acompanhado pelo aumento do valor da receita destas empresas que em 2013 atingiu o valor de $R \$ 82$ bilhões. Outra informação relevante obtida a partir da análise é que em 2007 o faturamento do setor de TI representava 35\% da receita do setor de telecomunicações em 2013 este valor atingiu $51 \%$.

No Brasil, os serviços de Tecnologia da Informação são classificados em cinco grupos: i) desenvolvimento de programas de computador sob encomenda; ii) desenvolvimento e licenciamento de programas de computador customizáveis; iii) desenvolvimento e licenciamento de programas de computador não customizáveis; iv) consultoria em tecnologia da informação; e v) suporte técnico, manutenção e outros serviços em tecnologia da informação (IBGE, 2017).

De maneira geral, o setor de Tecnologia da Informação vai além de um conjunto de hardware e software que tem, como função, o processamento das informações, mas também pode ser utilizado como suporte à gestão estratégica da informação. O setor se caracteriza ainda por possuir significativo valor adicionado, fazer uso de mão de obra altamente qualificada quando comparado a outros setores da economia, contribui em processos de inovação e promove forte interação entre produtor e usuário, ou seja, possibilita o desenvolvimento de estratégias de aprendizado através do relacionamento com outras empresas e setores.

\subsection{Estudos anteriores}

Alguns estudos relacionados à utilização do custeio alvo têm fornecido evidências empíricas sobre o tema no âmbito gerencial, e também com a abordagem da teoria contingencial. Nesse contexto, ao investigar se as mudanças no ambiente organizacional levaram a mudanças na estratégia das organizações, no design organizacional, na tecnologia avançada de manufatura e nas práticas de contabilidade gerencial, Baines e Langfield-Smith (2003) concluíram que um ambiente cada vez mais competitivo influencia na estratégia da organização, que por sua vez, influenciou mudanças no design organizacional, na tecnologia avançada de manufatura e nas práticas avançadas de contabilidade gerencial. 
O estudo de Ax et al. (2008) utilizou-se dos argumentos da teoria da contingência para investigar quais fatores estão relacionados à adoção do custeio alvo em empresas suecas de diversos setores. Os resultados do estudo indicaram que a adoção do custeio alvo e a intensidade da competição se relacionam positivamente, no entanto, não houve evidências de uma relação direta entre a incerteza ambiental percebida e a adoção do custeio alvo. Por sua vez, Marques (2012) examinou as deduções e inferências extraídas acerca da adoção, implementação e uso do custeio alvo em uma organização à luz da teoria da contingência e da nova sociologia institucional. Com relação a teoria contingencial concluiu-se que os fatores contingentes observados (ambiente, estratégia, porte, estrutura e tecnologia) favoreceram a adoção e utilização do custeio alvo.

Silva et al. (2014), por meio de um estudo de caso, buscaram investigar os fatores contingenciais presentes na organização e que poderiam ter influenciado a decisão de modificar o sistema de custeio. Segundo os autores, os resultados encontrados indicaram que as variáveis contingenciais ambiente, concorrência, mercado, tecnologia e sistema de controle gerencial influenciaram a decisão de modificação do sistema de custeio.

A pesquisa de Rasit e Ismail (2017) realizada com gerentes financeiros de empresas elétricas e eletrônicas da Malásia evidenciou que a intensidade percebida da competição, do avanço tecnológico e a estratégia de negócios influenciariam a adoção do custeio alvo. Ainda nesse sentido, Marques e Rocha (2017) desenvolveram um estudo para analisar as pesquisas que abordaram os fatores contingenciais que possuem relação com a adoção e uso do custeio alvo. As evidências encontradas destacaram que a intensidade da concorrência e a incerteza ambiental propicia a adoção e uso do custeio alvo, enquanto as estratégias investigadas apresentam resultados contraditórios nas pesquisas analisadas. Os autores ressaltaram ainda que as pesquisas investigadas são internacionais, indicando a falta de estudos com essa temática no contexto brasileiro.

Ao investigarem os fatores contingenciais que possivelmente influenciam no processo de sistemas de custeio alvo em organizações rurais, Brizolla et al. (2017) concluíram que o ambiente, tecnologia e estratégia influenciam no processo de custeio alvo das organizações, já que essas organizações atuam em ambiente dinâmico, em que a estrutura, a tecnologia e a estratégia são variáveis contingenciais que influenciam o sistema de custeio alvo. Já Gonçalves, Gaio e Silva (2018) examinaram à luz da teoria de contingência a relação entre a inovação e os determinantes ambientais e organizacionais na adoção do custeio alvo nas maiores empresas portuguesas. A pesquisa evidenciou que os determinantes previamente testados (competitividade, ambiente, incerteza e inovação) não são fatores suficientes nem necessários na utilização do sistema de custeio.

Com relação aos aspectos do custeio alvo na gestão de custos em micro e pequenas empresas do setor de informática e tecnologia, Bomfim, Callado e Callado (2018) identificaram que as características dos gestores de micro e pequenas empresas, como idade, formação e cargo ocupado, são fatores que influenciam na formalização estratégica e na adoção de técnicas estratégicas de gestão de custos, como o custeio alvo.

Quanto as pesquisas relacionadas ao custeio alvo com foco específico nas empresas prestadoras de serviços podem-se destacar o estudo de Camacho e Rocha (2008) que verificou a viabilidade de aplicação do custeio alvo em serviços hospitalares. Os resultados mostraram que o processo de custeio alvo pode ser aplicado, com sucesso, a entidades hospitalares. Já o estudo de Lemos Junior e Colauto (2013) buscou identificar a composição dos custos envolvidos na oferta e precificação de mensalidades de um curso de graduação por meio da aplicação do custeio direto e custeio alvo. Os autores indicaram que o uso de tal método pode proporcionar uma reestruturação dos serviços prestados, além de proporcionar uma melhoria no planejamento para aumento do faturamento.

Com base na literatura e nos estudos citados, observa-se a importância do entendimento dos fatores que propiciam a adoção e o uso do custeio alvo. No entanto, percebe-se a escassez de pesquisas sobre o tema, principalmente no âmbito brasileiro, e também com o foco no setor de serviços, indicando assim a necessidade desse tipo de pesquisa nas empresas dessa área.

\section{Metodologia}

A partir do objetivo proposto para esta pesquisa, foi realizada uma pesquisa descritiva com abordagem qualitativa. Para Andrade (1999), pesquisas descritivas buscam observar, registrar, analisar, classificar e interpretar aspectos inerentes a determinado fato que se pretende conhecer. Esta perspectiva é complementada por Gil (1999) ao afirmar que esta modalidade de pesquisa pode ir além da identificação de determinado fenômeno, mas também pode determinar sua natureza. Com relação a pesquisas qualitativas, Oliveira (2011) considera que elas se caracterizam pelo envolvimento de dados qualitativos e formas qualitativas de análises, enquanto Richardson (1999) e Martins e Theóphilo (2016) assinalam que este tipo de pesquisa busca compreensão de significados e características.

Esta pesquisa foi operacionalizada a partir de um estudo de caso. Sobre estudos de caso, Raupp e Beuren (2006) consideram que pesquisas desta natureza são preferidas por pesquisadores que desejam aprofundar seu conhecimento a respeito de determinado caso específico. Para Oliveira (2011), estudos de caso são abordagens apropriadas quando o objeto investigado está em seu contexto real e fora do controle 
do pesquisador. Segundo Martins e Theóphilo (2016), esta é uma estratégia de pesquisa que demanda avaliação qualitativa e tem como finalidade estudar uma unidade social de modo profundo e intenso.

O caso investigado foi uma empresa de consultoria de médio porte localizada na cidade do Rio de Janeiro (RJ) que atua no segmento de Tecnologia da Informação ( $\mathrm{TI}$ ). Esta empresa iniciou suas atividades em 2005 e também possui operações no Estado de São Paulo. Os serviços prestados pela empresa possuem alta especificidade e a empresa tem como objetivo orientar seus clientes a gerar valor ao seu negócio a partir da compreensão das necessidades relacionadas ao desenvolvimento de software. Alguns dos serviços prestados pela empresa são: análise de segurança de aplicações, automação de processos, automação de entregas, automação de testes, gestão e transformação do ciclo de vida de software e gerenciamento de performance de TI. O critério de escolha utilizado foi a acessibilidade para a coleta de informações e por se tratar de uma empresa do setor de serviços.

Para a operacionalização da coleta de dados desta pesquisa foram realizadas entrevistas. A entrevista é definida por Cervo, Bervian e Silva (2007, p. 51) como uma conversa orientada para um objetivo definido: recolher, por meio do interrogatório do informante, dados para a pesquisa". As entrevistas realizadas foram do tipo semiestruturadas, de acordo com Martins e Theóphilo $(2016$, p. 88) esse tipo de entrevista "é conduzida com uso de um roteiro, mas com liberdade de serem acrescentadas novas questões pelo entrevistador".

As entrevistas foram realizadas em duas visitas realizadas à empresa nos meses de novembro e dezembro de 2018. Participaram da pesquisa três pessoas: o gerente administrativo e dois colaboradores da área comercial. Foram escolhidas para participar da pesquisa pessoas envolvidas com o processo de negociação de serviços com os clientes. As entrevistas tiveram, em média, duração de 50 minutos e não foram gravadas e buscou-se compreender o processo de precificação da empresa e o uso do custeio alvo.

Durante as entrevistas também buscou-se verificar a percepção dos entrevistados a respeito dos fatores contingenciais (ambiente, tecnologia, estrutura e estratégia) na empresa e, para isso, foi utilizado um roteiro adaptado do estudo de Brizolla et al. (2017), no qual os entrevistados atribuíam conceitos específicos para cada fator. Sobre o fator ambiente (Figura 1) foi perguntado como percebiam o ambiente em que a empresa está inserida indicando um dos seguintes conceitos: muito estável, estável, pouco estável, pouco dinâmico, dinâmico ou muito dinâmico. Quanto ao fator tecnologia (Figura 2), buscou-se identificar se a empresa faz uso de ferramentas tecnológicas em relação às variáveis determinadas, sendo assim, o entrevistado atribuía: não usa, usa pouco, usa ou usa com intensidade. No aspecto estrutura (Figura 3), buscou-se verificar a percepção dos respondentes em relação a delegação de responsabilidades, atribuindose o conceito: nunca delega, delega pouco, delega ou delegação total. No fator estratégia (Figura 4), perguntou-se sobre o nível de prioridades estratégicas: não é importante, pouco importante, importante, muito importante. Além disso, foram investigados os atributos relacionados ao processo de custeio alvo no intuito de verificar a percepção dos respondentes sobre os componentes ou a razão de uso do método. Dessa forma, foi solicitado que respondessem 'sim' ou 'não' ou 'não se aplica' às características que consideravam presentes na empresa, conforme Figura 6.

Para a coleta das informações, foi utilizada a técnica de análise de conteúdo. Esta técnica é definida por Bardin como (1977, p. 42) "um conjunto de técnicas de análise das comunicações visando obter, por procedimentos sistemáticos e objetivos de descrição do conteúdo das mensagens, indicadores que permitam a inferência de conhecimentos às condições de produção/recepção destas mensagens". Sobre esta técnica, Vergara (2012) afirma que ela é utilizada com o objetivo de verificar o que está sendo dito sobre determinado tema.

É preciso ressaltar que os modos de uso das informações dessa pesquisa, provenientes das coletas nas entrevistas, garantem o anonimato dos entrevistados e da empresa investigada. A omissão do nome da organização e dos participantes da pesquisa é um direito garantido com intuito de garantir o respeito à questões éticas nas pesquisas em Ciências Sociais.

\section{Descrição e Análise dos Dados}

Com o uso de um roteiro adaptado do estudo por Brizolla et al. (2017), primeiramente buscou-se avaliar as variáveis contingenciais. Inicialmente foi analisada a categoria contingencial ambiente. $\mathrm{O}$ objetivo desta análise foi verificar se o ambiente em que a empresa está inserida é muito estável, isto é, com mudanças lentas e previsíveis ou se é muito dinâmico com mudanças rápidas e imprevisíveis. Dessa forma, para cada aspecto investigado os respondentes deveriam atribuir um conceito, de acordo com as características de dinamismo e previsibilidade do ambiente em que a empresa está inserida, abrangendo desde o ambiente ser considerado muito estável até ele ser muito dinâmico. Os resultados obtidos estão dispostos na Figura 1.

Com os resultados observados na Figura 1 pode-se depreender que a empresa está inserida em um ambiente muito dinâmico uma vez que três categorias são assim classificadas pelos respondentes, destacando-se a categoria 'tecnologia aplicada ao processo de prestação de serviço' que foi considerada muito dinâmica por todos os respondentes. O resultado possivelmente explica-se pelo setor de atuação da empresa que é a área da Tecnologia da Informação (TI), pois diante da rápida evolução tecnológica as 
empresas deste setor são caracterizadas pela busca da inovação para suprir às necessidades e às tendências do mercado.

\begin{tabular}{|l|c|}
\hline Categoria ambiente & Conceito atribuído \\
\hline a. Atitude da concorrência & Dinâmico \\
\hline b. Competição por mão de obra & Dinâmico \\
\hline c. Tecnologia aplicada ao processo de prestação de serviço & Muito dinâmico \\
\hline d. Restrições legais, políticas e econômicas do setor & Estável \\
\hline
\end{tabular}

Figura 1 - Aspecto contingencial ambiente

Fonte: Dados da pesquisa

Assim, como a organização está inserida em um ambiente relacionado à inovação, sendo também dinâmico e competitivo, torna-se importante a obtenção de mais informações para dar subsídio aos gestores em suas decisões estratégicas. Conforme Marques (2012) o dinamismo do setor explica a adoção do custeio alvo como forma de obtenção de informações mais acuradas para enfrentamento da concorrência. Este resultado corrobora com o estudo de Baines e Langfield-Smith (2003) confirmando que o ambiente cada vez mais competitivo influencia as práticas gerenciais adotadas pela organização.

Quanto ao aspecto 'restrições legais, políticas e econômicas', este foi considerado como estável. Tal resultado pode ser justificado pelo fato de o Estado adotar uma postura de incentivo a inovação tecnológica visando o crescimento econômico. Esses incentivos podem apontar em direção ao uso balanceado de combinação de políticas, influenciando assim para um ambiente mais estável.

A segunda categoria contingencial investigada foi a tecnologia, na qual buscou-se avaliar se a organização faz uso de algumas ferramentas e características tecnológicas. Os respondentes deveriam atribuir um conceito conforme o grau de intensidade de utilização.

\begin{tabular}{|l|c|}
\hline Categoria ambiente & Conceito atribuído \\
\hline a. Armazenamento de dados & Grande intensidade \\
\hline b. Troca de dados de forma eletrônica & Grande intensidade \\
\hline c. Sistema Integrado (ERP) & Não faz uso \\
\hline
\end{tabular}

Figura 2 - Aspecto contingencial tecnologia

Fonte: Dados da pesquisa

Os resultados apresentados na Figura 2 evidenciam que a tecnologia está muito presente na organização no entendimento dos respondentes, mas não totalmente uma vez que a empresa não faz uso da categoria 'sistema integrado (ERP)'. De acordo com Marques, no ambiente de alto uso de tecnologias a utilização do custeio alvo parece ser apropriado. Isso confirma os achados de Silva et al. (2014), Rasit e Ismail (2017), Brizolla et al. (2017) nos quais percebe-se que quanto mais características tecnológicas a organização possui maior a possibilidade de adoção da técnica de custeio alvo.

Como se trata de uma empresa onde a atividade principal é consultoria em TI esperava-se uma forte relação com o fator tecnologia (Figura 2), pois, a mesma trabalha diretamente com a coordenação, comunicação e processamento de informações de forma eletrônica. O uso de informações tanto dentro das organizações como entre as organizações tem apresentado um volume muito superior ao que as empresas estavam acostumadas, influenciando assim, em uma maior dependência de ferramentas tecnológicas de armazenamento de dados e de transferência eletrônica de informações. Assim, a tecnologia também busca facilitar o processamento dos dados desenvolvendo sistemas de gestão que auxiliem nas práticas empresariais. A utilização de um sistema de gestão faz-se importante de modo que a adoção de um método de gestão de custos como o custeio alvo possa ser implementado.

A empresa investigada indicou não fazer uso do sistema integrado (ERP), no entanto, segundo Chenhall (2003) a forma como as informações são geradas e as técnicas de controle utilizadas variam de organização para organização, pois, podem sofrer influência tanto da sua estrutura como das suas escolhas estratégicas.

Em relação a categoria contingencial estrutura procurou-se investigar o nível de delegação dos gerentes. Foi solicitado aos respondentes a aplicação de um conceito para os níveis de delegação presentes na empresa. Os resultados estão evidenciados na Figura 3.

\begin{tabular}{|l|c|}
\hline Categoria ambiente & Conceito atribuído \\
\hline a. Oferecimento de novos produtos & Há delegação \\
\hline b. Contratação e demissão de pessoal & Pouca delegação \\
\hline c. Seleção de investimentos relevantes & Nunca delega \\
\hline d. Decisões de preços & Pouca delegação \\
\hline
\end{tabular}

Figura 3 - Aspecto contingencial estrutura

Fonte: Dados da pesquisa

Dos resultados da Figura 3 é possível verificar a delegação está presente para a categoria de 'oferecimento de novos produtos'; pouca delegação para as categorias de 'contratação e demissão de 
pessoal' e 'decisões de preços' e não há delegação para a categoria 'seleção de investimentos relevantes'. De acordo com Chenhall (2003), a estrutura organizacional representa o posicionamento de fatores como hierarquização, setores, processos, pessoas, etc. Os conceitos atribuídos pelos respondentes com relação a estrutura organizacional da empresa estudada revelam indícios de uma organização com características de tomada de decisão descentralizada já que não apresenta muita delegação das tarefas.

Diante do fator contingencial estrutura, Marques (2012) argumenta que o custeio alvo é um processo aderente à estrutura organizacional descentralizada e que estimula o trabalho em equipes. Para Ellram (2002), o custeio alvo não é um esforço autônomo, ao contrário, é um processo mais efetivamente realizado por equipes multifuncionais, em conjunto com outros processos que agregam valor.

Seguindo para a análise da categoria contingencial estratégia, o intuito foi avaliar o nível de prioridades estratégicas da empresa atribuindo conceitos de acordo com o grau de importância atribuído pela organização no entender dos respondentes às prioridades estratégicas mencionadas.

\begin{tabular}{|l|c|}
\hline Categoria ambiente & Conceito atribuído \\
\hline a. Buscar alta qualidade dos produtos, muito mais que a concorrência & Muito importante \\
\hline b. Investir em pesquisa e desenvolvimento muito mais que a concorrência & Média importância \\
\hline c. Ter preço de venda menor que o da concorrência & Importante \\
\hline
\end{tabular}

Figura 4 - Aspecto contingencial estratégia

Fonte: Dados da pesquisa

A Figura 4 mostra que a categoria 'buscar alta qualidade dos produtos, muito mais que a concorrência' foi considerado como muito importante para a empresa na percepção dos respondentes. 'Ter preço de venda menor que o da concorrência' também é um aspecto tido como importante para empresa, enquanto que a categoria 'Investir em pesquisa e desenvolvimento muito mais que a concorrência' foi a categoria conceituada como média importância o que pode significar apenas que a organização atribui um menor grau de importância quando comparado aos aspectos anteriores. Tais resultados indicam que a empresa apresenta grande interesse em apresentar qualidade e buscar informações novas para responder as oportunidades potenciais do mercado. Essa estratégia adotada pode ser explicada pelo o fato das empresas do setor de TI estarem inseridas em um ambiente de inovação e alta competitividade.

Com relação ao custeio alvo, Marques (2012) constatou na literatura que o custeio alvo está muito ligado a gestão estratégica da empresa e desempenha um papel importante na gestão estratégica dos custos. As pesquisas de Brizolla et al. (2017) e Rasit e Ismail (2017) também evidenciaram que a estratégia influencia na adoção do custeio alvo.

Por fim, para a categoria contingencial porte foi utilizada a classificação do BNDES -Banco Nacional do Desenvolvimento (2018) conforme Figura 5. A empresa estudada foi classificada como média empresa uma vez que seu faturamento anual está no intervalo entre 4,8 milhões e 300 milhões de reais.

\begin{tabular}{|c|l|}
\hline Classificação & Receita operacional bruta anual \\
\hline Microempresa & Menor ou igual a $R \$ 360$ mil \\
\hline Pequena empresa & Maior que $R \$ 360$ mil e menor ou igual a $R \$ 4,8$ milhões \\
\hline Média empresa & Maior que $R \$ 4,8$ milhões e menor ou igual a $R \$ 300$ milhões \\
\hline Grande empresa & Maior que $R \$ 300$ milhões \\
\hline
\end{tabular}

Figura 5 - Classificação de porte de empresa

Fonte: BNDES (2018)

O porte é um fator que influencia na adoção do custeio alvo; quanto maior o porte mais a organização pode ser propensa ao uso desta ferramenta (Marques, 2017). Conforme a organização se torna maior, a necessidade de lidar com maiores quantidades de informações aumenta (Chenhall, 2003); e ainda, o aumento de tamanho de uma empresa tornará a sua estrutura organizacional mais complexa; podendo haver ampliação no nível de controle de gestão (Silva et al., 2014).

Assim como no estudo de Brizolla et al. (2017) buscou-se identificar na percepção dos respondentes sobre os atributos do sistema de custeio alvo, conforme Figura 6 , para o período estudado. No entanto, na percepção dos entrevistados observou-se que os atributos (componentes ou a razão de uso) do sistema de custeio alvo na organização estudada não estão todos presentes e houve divergência entre as respostas dadas.

Cabe ressaltar que o atributo 'Plano produção/suprimento e estocagem' apresentado na Figura 6 não se aplica à empresa uma vez que se trata de uma empresa de serviços e não possui estoques. Para o atributo 'premissas do sistema' dois dos respondentes entenderam que o mesmo está presente e um entende que não. É preciso destacar que durante a entrevista um dos entrevistados relatou que entende que esse atributo existe, porém não há documentos formais.

Apenas um dos entrevistados (B) respondeu positivamente em relação ao atributo 'previsão de cenários' e 'avaliação de desempenho'. E apenas o respondente $C$ entende que há a 'automação do processo de custeio'. Quanto ao plano de recursos humanos um respondente respondeu que sim e outro que não está presente; um dos entrevistados (B) durante a entrevista disse que em sua percepção está presente, mas de 
forma incipiente, logo, optou pelo não. Possivelmente a divergência nas respostas deve-se ao fato das diferentes funções desempenhadas pelos entrevistados o que pode implicar em percepções distintas.

\begin{tabular}{|c|c|c|c|}
\hline \multirow{2}{*}{ Componentes/razão de uso } & \multicolumn{3}{|c|}{ Entrevistados } \\
\cline { 2 - 4 } & A & B & C \\
\hline 1. Premissas do sistema & Não & Sim & Sim \\
\hline 2. Previsão de cenários & Não & Sim & Não \\
\hline 3. Plano de vendas & Sim & Sim & Sim \\
\hline 4. Plano de recursos humanos & Não & Não & Sim \\
\hline 5. Demonstrações contábeis projetadas & Sim & Sim & Sim \\
\hline 6. Automação do processo de custeio & Não & Não & Sim \\
\hline 7. Plano produção/suprimento e estocagem & NA & NA & NA \\
\hline 8. Planejamento Operacional & Sim & Sim & Sim \\
\hline 9. Avaliação de desempenho & Não & Sim & Não \\
\hline 10. Comunicação das metas & Sim & Sim & Sim \\
\hline
\end{tabular}

Figura 6 - Atributos do sistema de custeio alvo

Fonte: Dados da pesquisa

Em relação aos atributos 'plano de vendas', 'demonstrações contábeis projetadas', planejamento operacional' e 'comunicação de metas' todos responderam de forma positiva, ou seja, entendem que estão presentes. Durante a entrevista com o gerente administrativo ele mostrou à entrevistadora o programa desenvolvido e utilizado pela empresa para acompanhamento do andamento dos serviços. O sistema permite a consulta do desempenho de um projeto individualmente ou o cliente de uma forma geral, pois um cliente pode ter contratado vários serviços diferentes. O acompanhamento da margem de contribuição de cada projeto também é realizado por meio de planilhas eletrônicas e o sistema de custeio variável é utilizado. Também são elaboradas as demonstrações contábeis projetadas.

De modo geral, esses resultados sugerem que a maioria dos aspectos relacionados ao custeio alvo são conhecidos pelos entrevistados, ocorrendo ainda casos em que o aspecto é conhecido, no entanto, não é utilizado. Percebe-se ainda que a organização está atenta às condições do mercado, buscando ferramentas necessárias para alcançar as metas as metas de lucros e custos, além de utilizarem técnicas de custos semelhantes aos conceitos do custeio alvo, sendo adotados em circunstâncias de intensa competitividade e alta incerteza do ambiente.

Foi possível observar que a empresa faz uso de algumas etapas do custeio alvo apesar de não denominar dessa forma. A empresa elabora uma proposta para um determinado serviço sendo que, normalmente, o cliente busca negociar. Então, o gerente comercial junto com gerentes técnicos e diretoria buscam alterar componentes de custos de serviços, no caso, mão de obra direta, para conseguir atingir a uma composição de custos que possa alcançar a margem de lucro da empresa e o preço de venda desejado pelo cliente.

Verificou-se que a empresa precisa de um aperfeiçoamento no acompanhamento dos custos após o contrato assinado para garantir que o custo alvo seja alcançado e, até mesmo, mais economias de custos possam ser obtidas (melhoria contínua). Essa é uma etapa que a empresa precisa melhorar. É preciso um maior envolvimento da parte administrativa e técnica nessa etapa de modo a unir esforços para atingir o custo alvo.

\section{Considerações Finais}

O objetivo dessa pesquisa foi analisar a influência dos fatores contingenciais no sistema de custeio alvo de uma empresa prestadora de serviços no Estado do Rio de Janeiro Para alcançar o objetivo assinalado foram realizadas entrevistas semiestruturadas, nestas foi utilizado um roteiro adaptado do estudo de Brizolla et al. (2017).

As categorias contingenciais verificadas foram ambiente, tecnologia, estratégia, estrutura e porte. No tocante a categoria ambiente a empresa está inserida em um setor dinâmico no qual a atitude da concorrência, competição por mão de obra e tecnologia aplicada ao processo de serviço com alto grau de dinamismo, ou seja, não estáveis. Apenas o aspecto referente as restrições legais, políticas e econômicas do setor foi tido como muito estável. Conforme literatura o dinamismo do setor favorece a adoção do processo de custeio alvo.

Em relação a categoria contingencial tecnologia na percepção dos entrevistados é um fator que está muito presente na realização das atividades da organização. O que faz todo o sentido pois a empresa estudada se trata de uma consultoria em TI. No entanto, verificou-se que a categoria que tratou do 'sistema integrado (ERP)' não foi reconhecido o uso pela empresa o que indica que a organização precisa melhorar nesse aspecto. $O$ uso elevado de tecnologias é um ambiente propício a utilização do custeio alvo conforme pesquisas anteriores. No que se refere a categoria estrutura, os entrevistados percebem a organização razoavelmente descentralizada. Por meio dos conceitos atribuídos pelos respondentes observa-se a presença 
da delegação de autoridade. A literatura indica que o custeio alvo tem aderência a um ambiente descentralizado uma vez que também estimulará para o trabalho em equipe.

Os resultados da categoria estratégia evidenciam-se a elevada importância atribuída pela empresa às estratégias mencionadas. Verificou-se que a empresa considera como muito importante a busca da alta qualidade em seus serviços isso se justifica pelas características dos serviços prestados pela organização que na maior parte das vezes tratar-se de serviços customizados. Possuir um preço de venda que enfrente a concorrência também foi tido como relevante também. Verificou-se no referencial teórico que o custeio está relacionado à gestão estratégica de uma organização.

Por fim, referente à categoria porte utilizou-se a classificação do BNDES que baseia na receita bruta anual auferida, dessa forma, a empresa estudada foi considerada como uma empresa de médio porte. As pesquisas constatam que quanto maior o porte maior a propensão da adoção do processo de custeio alvo. Já em relação aos atributos ou a razão do uso do sistema de custeio alvo verificou-se algumas divergências nas respostas dos entrevistados. Apenas os atributos 'plano de vendas', 'demonstrações contábeis projetadas', planejamento operacional' e 'comunicação de metas' foram entendidos como presentes. Uma explicação possível para as diferenças pode ser as funções desempenhadas por cada entrevistado o que pode limitá-lo em certos aspectos de uso do sistema de custeio alvo.

Durante as entrevistas pode-se comprovar nas falas dos entrevistados a importância do sistema de custeio alvo no alcance de um custo alvo e principalmente de um preço competitivo. Dessa forma, verificouse a influência das categorias contingenciais na adoção de uma ferramenta de controle gerencial no caso em questão o custeio alvo. Foi possível observar como tais aspectos podem contribuir e estimular a sua adoção.

Essa pesquisa por se tratar de um estudo de caso possui como limitação a impossibilidade de que os resultados encontrados possam ser estendidos a outras organizações por ser um estudo baseado nas percepções dos entrevistados. Sugere-se que outros estudos sejam realizados em empresas prestadoras de serviços de $\mathrm{Tl}$ a fim de conhecer as práticas de contabilidade gerenciais utilizadas por essas organizações.

\section{Referências}

Andrade, M. M. de. (1999). Introdução à metodologia do trabalho científico. São Paulo: Atlas.

Ax, C., Greve, J., \& Nilsson, U. (2008). The impact of competition and uncertainty on the adoption of target costing. International Journal of Production Economics, 115(1), 92-103.

https://doi.org/10.1016/.i.jpe.2008.04.010

Baines, A., \& Langfield-Smith, K. (2003). Antecedents to management accounting change: a structural equation approach. Accounting, Organizations and Society, 28(7-8), 675-698.

https://doi.org/10.1016/S0361-3682(02)00102-2

Bardin, L. (1977). Análise de Conteúdo (LA Reto, \& A. Pinheiro, Trad.) Lisboa: Edições 70.

Berts, K.; Kock, S. (1995). Implementation considerations for activity-based cost systems in service firms the unavoidable challenge. Management Decision, 33(6), 57-63.

https://doi.org/10.1108/00251749510087669

BNDES. Banco Nacional do Desenvolvimento. (2018). Disponível em:

https://www.bndes.gov.br/wps/portal/site/home/faq/apoiofinanceiro/1944455039/2134060738/1782308253.

Acesso em: 20 Dez. 2018.

Bueren, I. M., \& Fiorentin, M. (2014). Influência de Fatores Contingenciais nos Atributos do Sistema de Contabilidade Gerencial: um estudo em empresas têxteis do Estado do Rio Grande do Sul. Revista de Ciências da Administração, 16(38), 196-212.

https://doi.org/10.5007/2175-8077.2014v16n38p195

Bomfim, E. T., Callado, A. A. C., \& Callado, A. L. C. (2018). Aspectos do custeio alvo na gestão de custos: um estudo em micro e pequenas empresas do setor de informática e tecnologia de Campina Grande-PB. In Anais do Congresso Brasileiro de Custos-ABC.

Brizolla, M. M. B., Chiarello, T. C., Fasolin, L. B., \& da Rosa, F. S. (2017). Custeio alvo sob o enfoque da Teoria Contingencial em organizações agrícolas. Custos e @gronegócio on line, 13(2), 354-385.

Cadez, S., \& Guilding, C. (2008). An exploratory investigation of an integrated contingency model of strategic management accounting. Accounting, Organizations and Society, 33(7-8), 836-863.

https://doi.org/10.1016/j.aos.2008.01.003 
Camacho, R. R., \& Rocha, W. (2008). Custeio-alvo em serviços hospitalares um estudo sob o enfoque da gestão estratégica de custos. Revista Contabilidade \& Finanças, 19(47), 19-30.

https://doi.org/10.1590/S1519-70772008000200003

Camacho, R. R. (2010). Fatores condicionantes da gestão de custos interorganizacionais na cadeia de valor de hospitais privados no Brasil: uma abordagem à luz da Teoria da Contingência (Doctoral dissertation, Universidade de São Paulo).

Cervo, A. L., Bervian, P. A. \& Silva, R. (2007). Metodologia científica. São Paulo: Pearson Prentice Hall, 2007.

Chapman, C. S. (1997). Reflections on a contingent view of accounting. Accounting, Organizations and Society, 22(2), 189-205. https://doi.org/10.1016/S0361-3682(97)00001-9

Chen, R. C., \& Chung, C. H. (2002). Cause-effect analysis for target costing. Management Accounting Quarterly, 3(2), 1-9.

Chenhall, R. H. (2003). Management control systems design within its organizational context: findings from contingency-based research and directions for the future. Accounting, Organizations and Society, 28(2-3), 127-168. https://doi.org/10.1016/S0361-3682(01)00027-7

Cooper, R. (1996). Costing techniques to support corporate strategy: evidence from Japan. Management Accounting Research, 7(2), 219-246. https://doi.org/10.1006/mare.1996.0013

Donaldson, L. (2007). Teoria da contingência estrutural. In: CLEGG, S. R. et al. (Org.). Handbook de Estudos Organizacionais: modelos de análise e novas questões em estudos organizacionais, 1, São Paulo, Atlas.

Gagne, M. L.; Discenza, R. (1995). Target costing. Journal of Business \& Industrial Marketing, 10(1), 16-22. https://doi.org/10.1108/08858629510081559

Gil, A. C. (1999). Pesquisa social. São Paulo: Atlas.

Guerreiro, R., Pereira, C. A., \& Rezende, A. J. (2006). Em busca do entendimento da formação dos hábitos e das rotinas da contabilidade gerencial: um estudo de caso. RAM. Revista de Administração Mackenzie, 7(2), 78-101. https://doi.org/10.1590/1678-69712006/administracao.v7n2p78-101

Gonçalves, T., Gaio, C., \& Silva, M. (2018). Target costing and innovation-exploratory configurations: A comparison of fsQCA, multivariate regression, and variable cluster analysis. Journal of Business Research, 89(8), 378-384. https://doi.org/10.1016/j.jbusres.2018.01.054

Ellram, L. M. (2002). Supply management's involvement in the target costing process. European Journal of Purchasing \& Supply Management, 8(4), 235-244. https://doi.org/10.1016/S0969-7012(02)00019-9

Everaert, P., Loosveld, S., Van Acker, T., Schollier, M., \& Sarens, G. (2006). Characteristics of target costing: theoretical and field study perspectives. Qualitative Research in Accounting \& Management, 3(3), 236-263.

Feil, P., Yook, K. H., \& Kim, I. W. (2004). Japanese target costing: a historical perspective. International Journal of Strategic Cost Management, 11(1), 10-19.

Gopalakrishnan, M., Samuels, J., \& Swenson, D. (2007). Target costing at a consumer products company: this global manufacturer uses it to introduce new products. Strategic Finance, 37-42.

Heineke, J., \& Davis, M. M. (2007). The emergence of service operations management as an academic discipline. Journal of Operations Management, 25(2), 364-374.

https://doi.org/10.1016/i.jom.2006.11.003

IBGE - Instituto Brasileiro de Geografia e Estatística. Serviços. Brasília, 2017. Disponível em: http://brasilemsintese.ibge.gov.br/servicos.html. Acesso em: 04 Nov. 2020.

Kato, Y. (1993). Target costing support systems: lessons from leading Japanese companies. Management Accounting Research, 4(1), 33-47. https://doi.org/10.1006/mare.1993.1002 
Lacity, M. C., \& Leslie P. W. (2017). A new approach to automating services. MIT Sloan Management Review, Fall.

Lemos Junior, L. C., \& Colauto, R. D. (2013). Target Costing e custeio direto em instituição confessional de ensino: uma aplicação no curso de graduação em administração. Revista Espacios, 34(1).

Manzanares, M. A. B., Molina, E. C., \& Fernández, L. C. (2001). El coste objetivo como modelo para la gestión de costes en la empresa. In Cruzando fronteras: tendencias de contabilidad directiva para el siglo XXI. Actas VII Congreso Internacional de Costos y II Congreso de la Asociación Española de Contabilidad Directiva.

Marques, K. C. M., \& Rocha, W. (2017). Knowledge construction on target costing: an analysis of surveys on factors that enhance its adoption and use. Revista Contemporânea de Contabilidade, 14 (32), 3-20. DOI: http://dx.doi.org/10.5007/2175-8069.2017v14n32p3

Marques, K. C. M. (2012). Custeio alvo à luz da teoria da contingência e da nova sociologia institucional: estudo de caso sobre sua adoção, implementação e uso (Doctoral dissertation, Universidade de São Paulo).

Martins, G. D. A., \& Theóphilo, C. R. (2016). Metodologia da investigação científica para ciências sociais aplicadas. São Paulo: Atlas.

Negri, J. A. de; Kubota, L. C. (org.). Estrutura e Dinâmica do Setor de Serviços no Brasil. IPEA - Instituto de Pesquisa Econômica e Aplicada, Brasília, 2006. Recuperado em 10 dezembro, 2018, de

http://www.ipea.gov.br/portal/index.php?option=com content\&view=article\&id=5513

Oliveira, A. B. S. (2011). Métodos da pesquisa contábil. São Paulo: Atlas, 81.

Porporato, M., \& Waweru, N. (2011). La teoría de la contingencia en contabilidad de gerencial: un repaso de la literatura anglosajona. Revista Iberoamericana de Contabilidad de Gestión, 9(17), 1-16.

Raupp, F. M., \& Beuren, I. M. (2006). Metodologia da Pesquisa Aplicável às Ciências. Como elaborar trabalhos monográficos em contabilidade: teoria e prática. São Paulo: Atlas, 76-97.

Richardson, R. J. (1999). Pesquisa social: métodos e técnicas. São Paulo: Atlas.

Rocha, W., \& Martins, E. A. (1998). Custeio alvo (target costing). In Anais do Congresso Brasileiro de Custos- $A B C$.

Rasit, Z. A., \& Ismail, K. (2017). Incorporating contingency theory in understanding factors influencing target costing adoption. Advanced Science Letters, 23(8), 7804-7808. https://doi.org/10.1166/asl.2017.9581

Sakurai, M. (1997). Gerenciamento integrado de custos. São Paulo. Atlas.

Sandoval, L. S. G. (2013). Los enfoques de sistemas de la administración y las contingencias: como contribuyen al buen funcionamiento de la empresa. Revista Estratégia Organizacional, 2(1) 55-62. https://doi.org/10.22490/25392786.1481

Santos, W. dos. O avanço da Tecnologia da Informação como serviço Disponível em: https://economiadeservicos.com/tag/estrutura-do-setor-de-servicos/. Acesso em: 12 Dez. 2018.

Sebrae - Serviço Brasileiro de apoio às Micro e Pequenas Empresas. PIB (2018). Disponível em: http://datasebrae.com.br/pib/\#setores. Acesso em: 04 Nov. 2020.

Silva, M. Z., Scarpin, J. E., Rocha, W., \& Di Domenico, D. (2014). Fatores contingenciais que contribuem para a decisão de modificação do sistema de custeio: estudo de caso em uma indústria moageira. Revista de Administração, 49(2), 267-279. https://doi.org/10.5700/rausp1145

Vergara, S. C. (2012). Métodos de pesquisa em administração. São Paulo: Atlas. 


\section{NOTAS}

\section{AGRADECIMENTOS}

Agradecemos ao Programa de Pós Graduação em Ciências Contábeis da Universidade Federal da Paraíba (PPGCCT/UFPB) pela oportunidade em desenvolver o estudo durante o curso.

\section{CONTRIBUIÇÃO DE AUTORIA}

Concepção e elaboração do manuscrito: E. C. Braga, J. F. Nascimento, A. A. C. Callado

Coleta de dados: E. C. Braga

Análise de dados: E. C. Braga, J. F. Nascimento, A. A. C. Callado

Discussão dos resultados: E. C. Braga, J. F. Nascimento, A. A. C. Callado

Revisão e aprovação: E. C. Braga, J. F. Nascimento, A. A. C. Callado

\section{CONJUNTO DE DADOS DE PESQUISA}

Todo o conjunto de dados que dá suporte aos resultados deste estudo foi publicado no próprio artigo.

\section{FINANCIAMENTO}

Não se aplica.

\section{CONSENTIMENTO DE USO DE IMAGEM}

Não se aplica.

\section{APROVAÇÃO DE COMITÊ DE ÉTICA EM PESQUISA}

Não se aplica.

\section{CONFLITO DE INTERESSES}

Não se aplica.

\section{LICENÇA DE USO}

Os Direitos Autorais para artigos publicados neste periódico são do autor, com direitos de primeira publicação para a Revista. Em virtude de aparecerem nesta Revista de acesso público, os artigos são de uso gratuito, com atribuições próprias, em aplicações educacionais, de exercício profissional e para gestão pública. A Revista adotou a licença Creative Commons Atribuição 4.0 Internacional - CC BY NC ND. Esta licença permite acessar, baixar (download), copiar, imprimir, compartilhar, reutilizar e distribuir os artigos desde que com a citação da fonte, atribuindo os devidos créditos de autoria. Nesses casos, nenhuma permissão é necessária por parte dos autores ou dos editores. Autores têm autorização para assumir contratos adicionais separadamente, para distribuição não-exclusiva da versão do trabalho publicada nesta revista (ex.: publicar em repositório institucional ou um capítulo de livro).

\section{PUBLISHER}

Universidade Federal de Santa Catarina. Curso de Ciências Contábeis e Programa de Pós-graduação em Contabilidade. Publicação no Portal de Periódicos UFSC. As ideias expressadas neste artigo são de responsabilidade de seus autores, não representando, necessariamente, a opinião dos editores ou da universidade.

\section{EDITORES}

Carlos Eduardo Facin Lavarda e Suliani Rover

\section{HISTÓRICO}

Recebido em: 31/07/2020 - Revisado por pares em: 27/10/2020 - Reformulado em: 28/11/2020 Recomendado para publicação em: 21/01/2021 - Publicado em: 22/03/2021

Uma versão preprint do artigo foi apresentada no XXVI Congresso Brasileiro de Custos, 2019. 